\title{
BETON BERMUTU DAN RAMAH LINGKUNGAN DENGAN MEMANFAATKAN LIMBAH ABU BAN BEKAS
}

\author{
Johan Oberlyn Simanjuntak ${ }^{1}$, Tiurma Elita Saragi ${ }^{2}$, \\ Ros Anita Sidabutar ${ }^{3}$, Humisar Pasaribu ${ }^{4}$, Rido Parulian Simbolon ${ }^{5}$ \\ Fakultas Teknik Universitas HKBP Nommensen, Medan \\ Email: oberlyn.simanjuntak@yahoo.co.id ${ }^{1}$, saragih_27@yahoo.com ${ }^{2}$, \\ rosanita_sidabutar@yahoo.com ${ }^{3}$, pasaribu.humisar@yahoo.com ${ }^{4}$, rido.sim@gmail.com ${ }^{5}$
}

\begin{abstract}
The need for housing is increasing day by day. This is a factor in the visit to the need for concrete as a housing construction material. The more concrete that is produced, the more cement is needed for the construction. Concrete is a composite material (mixture) of several materials, the main ingredient of which consists of a mixture of cement, fine aggregate, coarse aggregate and water. Utilization of waste tire ash in the concrete mix is one of the alternative uses so that ic can ultimately increase the efficiency of cement savings which takes a long time to increase in high prices. With reference to this, this study uses used waste as a cement additive with a mixture composition of $0 \%, 3 \%, 6 \%$ and $9 \%$. The test specimens were made using a cylinder with a diameter of $15 \mathrm{~cm}$ and a height of $40 \mathrm{~cm}$ with 48 specimens produced. The results of the compressive strength test of normal concrete $(25.45 \mathrm{MPa})$, while the concrete with a mixture of $3 \%$ used tire ash (28.15 MPa), 6\% used tire ash mixture $(23.46 \mathrm{MPa})$ and $9 \%$ used tire ash mixture $(18.60 \mathrm{MPa})$. From this research, it can be said that compressive strength of concrete using $3 \%$ ash produces the greatest compressive strength of $28.15 \mathrm{MPa}$.
\end{abstract}

Keywords : Concrete, Eco Friendly, Compressive Strength

\section{PENDAHULUAN}

Pada dunia konstruksi, beton masih berperan penting sebagai material utama yang digunakan. Hal ini dikarenakan beton memiliki beberapa kelebihan seperti kemudahan dalam pengerjaan, kuat tekan yang tinggi, dan memiliki nilai ekonomis dalam pembuatan dan perawatannya. Namun terdapat beberapa kelemahan beton antara lain rendahnya kemampuan menahan beban tarik karena beton merupakan bahan yang getas (brittle). Sifat beton yang getas menyebabkan beton akan segera retak jika mendapat gaya gaya tarik yang tidak terlalu besar.

Ban bekas merupakan salah satu bahan buangan dan bekas pakai yang dapat mudah dicari dan ditemukan disetiap daerah di Indonesia dan jumlahnya relatif cukup tinggi. Pada sisi lain pemanfaatan ban karet di Indonesia masih sangat terbatas, antara lain 
hanya untuk pelindung dermaga (fender), tali, sendal, tempat sampah dan kerajinan kursi dan lain-lain.

Semakin meningkatnya industri otomotif seiring dengan meningkatnya kebutuhan produksi ban menyebabkan semakin banyak limbah ban yang tidak dapat diuraikan oleh karena itu menggunakan limbah ban sebagai pengganti material dalam beton menjadi salah satu jalan keluar. Ban karet sendiri memiliki modulus elastisitis 0,77-1,33 MPa dan memiliki density yang rendah yaitu berkisar antar $1,08-1,27 \mathrm{t} / \mathrm{m}^{3}$.

Penelitian ini dilakukan dengan menggunakan limbah ban karet sebagai bahan campuran beton sehingga pada akhirnya penelitian ini bertujuan untuk mengetahui cara mengolah limbah abu bekas bakaran ban bekan sehingga dapat digunakan menjadi beton yang berkualitas dan ramah lingkungan sekaligus untuk mengetahui kegunaan beton yang diolah dari abu bekas bakan ban bekas.

\section{METODE PENELITIAN}

Dalam penelitian ini metode yang digunakan adalah metode ekperimental laboratorium dengan cara membandingkan beton normal f'c $=25 \mathrm{MPa}$ sebagai kontrol dengan beton yang campurannya ditambahkan abu limbah ban karet. Hasil pengamatan diharapkan dapat mengetahui pengaruh penambahan abu ban karet terhadap kekuatan beton.

Bahan baku yang digunakan untuk benda uji beton pada penelitian ini adalah :

1) Semen Padang Tipe I kemasan 50 kg;

2) Agregat kasar / batu pecah dari KIM 2 dengan ukuran $\pm 1-2 \mathrm{~cm}$;

3) Agregat halus / pasir dari daerah Binjai yang disaring terlebih dahulu untuk menentukan zona pasir dan kandungan lumpurnya;

4) Air yang secara visual tampak jernih, tidak berwarna dan tidak berbau;

5) Limban Ban Karet yaitu ban karet bekan yang dibakar kemudian abu bekas pembakarannya disaring 
Pada penelitian ini jumlah sampel benda uji ditentukan masing-masing 3 buah sampel tiap variannya. Adapun varian dari masing-masing benda uji dijelaskan pada Tabel 4.

Tabel 4. Jumlah Sampel Benda Uji

\begin{tabular}{|l|c|c|c|c|c|}
\hline \multirow{2}{*}{ Kelompok Benda Uji } & \multicolumn{4}{|c|}{$\begin{array}{c}\text { Jumlah Pengujian Kuat Tekan } \\
\text { Pada Umur }\end{array}$} & $\begin{array}{c}\text { Jumlah } \\
\text { Benda Uji } \\
\text { (buah) }\end{array}$ \\
\cline { 2 - 5 } & $\mathbf{7 ~ h a r i ~}$ & $\mathbf{1 4}$ hari & $\mathbf{2 1}$ hari & $\mathbf{2 8}$ hari & 12 \\
\hline Beton Normal & 3 & 3 & 3 & 3 & \\
\hline Beton Eksperimen & & & & & 12 \\
$-3 \% \mathrm{BN}$ & 3 & 3 & 3 & 3 & 12 \\
- - 6\% BN & 3 & 3 & 3 & 3 & 12 \\
\hline$-9 \% \mathrm{BN}$ & 3 & 3 & 3 & 3 & $\mathbf{4 8}$ \\
\hline \multicolumn{1}{|c|}{ Jumlah } & $\mathbf{1 2}$ & $\mathbf{1 2}$ & $\mathbf{1 2}$ & $\mathbf{1 2}$ & \\
\hline
\end{tabular}

Sumber : Hasil penelitian (2020)

Perencanaan campuran adukan beton, proporsi campuran koreksi dan perencanaan pembuatan 12 benda uji yang digunakan pada penelitian dijabarkan pada Tabel 5, Tabel 6 dan Tabel 7.

Tabel 5. Perencanaan Campuran Adukan Beton

\begin{tabular}{|c|l|l|}
\hline No. & \multicolumn{1}{|c|}{ Uraian } & \\
\hline 1. & Kuat tekan yang disyaratkan pada umur 28 hari (f'c) & $25 \mathrm{MPa}$ \\
\hline 2. & Deviasi standar (s) & $7 \mathrm{MPa}$ \\
\hline 3. & Nilai tambah (m) & $11,5 \mathrm{MPa}$ \\
\hline 4. & Kuat tekan rata-rata yang direncanakan (f'cr) & $36,5 \mathrm{MPa}$ \\
\hline 5. & Jenis semen & Tipe I \\
\hline 6. & Jenis agregat : & \\
& - Agregat kasar & Batu pecah \\
& - Agregat halus & Alami \\
\hline 7. & Faktor air semen : & \\
& - Cara 1 & $0,43(\mathrm{grafik})$ \\
& - Cara 2 & $0,52(\mathrm{tabel})$ \\
\hline 8. & - Fas maksimal & $0,6(\mathrm{syarat})$ \\
\hline 9. & Nilai slump & 0,43 \\
\hline 10. & Ukuran agregat maksimum & $30-60 \mathrm{~mm}$ \\
\hline 11. & Kadar air bebas & $40 \mathrm{~mm}$ \\
\hline 12. & Jumlah semen & $170 \mathrm{~kg} / \mathrm{m}^{3}(\mathrm{tabel})$ \\
\hline 13. & Jumlah semen maksimal & $395,55 \mathrm{~kg} / \mathrm{m}^{3}$ \\
\hline
\end{tabular}




\begin{tabular}{|c|l|l|}
\hline 14. & Jumlah semen minimum & $275 \mathrm{~kg} / \mathrm{m}^{3}$ \\
\hline 15. & Jumlah semen yang dipakai & $395,55 \mathrm{~kg} / \mathrm{m}^{3}$ \\
\hline 16. & Faktor air semen yang disesuaikan & 0,43 \\
\hline 17. & Susunan butiran agregat halus & Daerah gradasi II \\
\hline 18. & Berat jenis : & $2 \mathrm{gr} / \mathrm{cm}^{3}$ \\
& - Agregat kasar & $2,2 \mathrm{gr} / \mathrm{cm}^{3}$ \\
& - Agregat halus & $35 \%$ \\
\hline 19. & Persentase agregat halus & $2,1 \mathrm{gr} / \mathrm{cm}^{3}$ \\
\hline 20. & Berat jenis SSD & $2380 \mathrm{~kg} / \mathrm{m}^{3}$ \\
\hline 21. & Berat isi beton & $1814,65 \mathrm{~kg} / \mathrm{m}^{3}$ \\
\hline 22. & Kadar air gabungan & $635,12 \mathrm{~kg} / \mathrm{m}^{3}$ \\
\hline 23. & Kadar agregat kasar & $1179,53 \mathrm{~kg} / \mathrm{m}^{3}$ \\
\hline 24. & Kadar agregat halus & \\
\hline
\end{tabular}

Sumber : Hasil penelitian (2020)

Tabel 6. Proporsi Campuran Koreksi

\begin{tabular}{|l|c|c|c|c|c|}
\hline \multirow{2}{*}{ Jumlah bahan } & \multirow{2}{*}{ Semen } & \multirow{2}{*}{ Air } & \multicolumn{2}{|c|}{ Agregat kering SSD } & \multirow{2}{*}{ Berat isi } \\
\cline { 3 - 5 } & & & Kasar & Halus & \\
\hline Tiap $\mathrm{m}^{3}$ & 395,53 & 206,293 & 1155,93 & 622,4176 & 2380,1706 \\
\hline Tiap benda uji $0,12 \mathrm{~m}^{3}$ & 47,442 & 24,755 & 138,7116 & 74,69 & 1534,003 \\
\hline
\end{tabular}

Sumber : Hasil penelitian (2020)

\begin{tabular}{|c|c|c|c|c|}
\multicolumn{5}{|c|}{ Tabel 7. Benda Uji } \\
\hline $\begin{array}{c}\text { Berat semen } \\
\text { per } \\
\text { pengecoran } \\
(\mathbf{k g})\end{array}$ & \multicolumn{4}{|c|}{ Berat material (kg) } \\
\cline { 2 - 5 } & Beton normal & $\begin{array}{c}\text { Beton abu ban } \\
\text { bekas } \\
\mathbf{3 \%}\end{array}$ & $\begin{array}{c}\text { Beton abu ban } \\
\text { bekas } \\
\mathbf{6 \%}\end{array}$ & $\begin{array}{c}\text { Beton abu ban } \\
\text { bekas } \\
\mathbf{9 \%}\end{array}$ \\
\hline 2,292 & 27,504 & 0,82512 & 1,65024 & 2,47536 \\
\hline
\end{tabular}

Sumber : Hasil penelitian (2020)

\section{ANALISIS DAN HASIL}

\section{Pengujian Agregat Kasar Dan Agregat Halus}

Hasil pengujian karakteristik agregat halus dan agregat kasar pada bahan campuran adukan beton pada penelitian dijabarkan pada Tabel 8 dan Tabel 9.

Tabel 8. Rekapitulasi Hasil Pengujian Agregat Halus

\begin{tabular}{|c|l|c|c|c|}
\hline No. & $\begin{array}{c}\text { Karakteristik agregat } \\
\text { halus }\end{array}$ & $\begin{array}{c}\text { Interval } \\
\text { spesifikasi }\end{array}$ & $\begin{array}{c}\text { Hasil } \\
\text { Pengamatan }\end{array}$ & Keterangan \\
\hline 1. & Kadar lumpur & maks. 5\% & $1,67 \%$ & memenuhi \\
\hline
\end{tabular}




\begin{tabular}{|c|c|c|c|c|}
\hline 2. & Kadar organik & $<$ No. 3 & No. 1 & memenuhi \\
\hline 3. & Kadar air & $2 \%-5 \%$ & $3,745 \%$ & memenuhi \\
\hline 4. & $\begin{array}{l}\text { Berat volume : } \\
\text { a) Kondisi lepas } \\
\text { b) Kondisi penggoyangan } \\
\text { c) Kondisi perojokkan }\end{array}$ & $\begin{array}{l}1,6-1,9 \mathrm{gr} / \mathrm{cm}^{3} \\
1,6-1,9 \mathrm{gr} / \mathrm{cm}^{3} \\
1,6-1,9 \mathrm{gr} / \mathrm{cm}^{3}\end{array}$ & $\begin{array}{c}1,445 \\
1,37 \\
1,56 \\
\end{array}$ & $\begin{array}{l}\text { memenuhi } \\
\text { Memenuhi } \\
\text { memenuhi }\end{array}$ \\
\hline 5. & Absorpsi & maks. $2 \%$ & $3,46 \%$ & memenuhi \\
\hline 6. & $\begin{array}{l}\text { Berat jenis : } \\
\text { a) } \mathrm{Bj} \mathrm{SSD} \\
\text { b) } \mathrm{Bj} \text { kering } \\
\text { c) Bj semu }\end{array}$ & $\begin{array}{l}1,6-3,3 \\
1,6-3,3 \\
1,6-3,3\end{array}$ & $\begin{array}{c}2,02 \\
2,16 \\
2,078\end{array}$ & $\begin{array}{l}\text { memenuhi } \\
\text { memenuhi } \\
\text { memenuhi }\end{array}$ \\
\hline 7. & Modulus kehalusan & $1,50-3,80$ & 2,18 dan 2,378 & memenuhi \\
\hline
\end{tabular}

Tabel 9. Rekapitulasi Hasil Pengujian Agregat Kasar

\begin{tabular}{|c|l|c|c|l|}
\hline No. & \multicolumn{1}{|c|}{$\begin{array}{c}\text { Karakteristik agregat } \\
\text { halus }\end{array}$} & $\begin{array}{c}\text { Interval } \\
\text { spesifikasi }\end{array}$ & $\begin{array}{c}\text { Hasil } \\
\text { Pengamatan }\end{array}$ & Keterangan \\
\hline 1. & Kadar air & $2 \%-5 \%$ & $2,8 \%$ & memenuhi \\
\hline 2. & $\begin{array}{l}\text { Berat volume : } \\
\text { d) Kondisi lepas }\end{array}$ & $1,6-3,3 \mathrm{gr} / \mathrm{cm}^{3}$ & 1,4 & memenuhi \\
& e) Kondisi penggoyangan & $1,6-1,9 \mathrm{gr} / \mathrm{cm}^{3}$ & 1,785 & Memenuhi \\
& f) Kondisi perojokkan & $1,6-1,9 \mathrm{gr} / \mathrm{cm}^{3}$ & 1,59 & memenuhi \\
\hline 3. & Absorpsi & maks. $4 \%$ & $2,51 \%$ & memenuhi \\
\hline 4. & Berat jenis : & $1,6-3,3$ & 2 & memenuhi \\
& d) Bj SSD & $1,6-3,3$ & 1,86 & memenuhi \\
& e) Bj kering & $1,6-3,3$ & 1.83 & memenuhi \\
\hline 5. & f) Bj semu & - & 26,56 & - \\
\hline 6. & Modulus kehalusan & $6-7,1$ & 3,5266 dan 3,5628 & memenuhi \\
\hline
\end{tabular}

Sumber : Hasil penelitian (2020)

Berdasarkan uraian hasil pengamatan terhadap pengujian agregat kasar dan agregat halus yang digunakan pada campuran adukan beton untuk penelitian ini ditemukan bahwa baik agregat halus maupun agregat kasar telah memenuhi standar dan layak untuk digunakan pada campuran adukan beton.

\section{Pengujian Kehalusan Semen Dan Abu Ban Bekas}

Hasil pengujian kehalusan semen dan abu ban bekas dijabarkan pada Tabel 10.

Tabel 10. Hasil Pengujian Kehalusan Semen dan Abu Ban Bekas

\begin{tabular}{l|l|l} 
Saringan & Berat tertahan (gr) & Kehalusan (\%)
\end{tabular}




\begin{tabular}{|l|c|c|c|c|}
\hline & Semen & Abu ban bekas & Semen & Abu ban bekas \\
\hline No. 100 & 0 & 42 & 0 & 84 \\
\hline No. 200 & 0,95 & 4,5 & 19 & 9 \\
\hline PAN & 40,5 & 3,5 & 81 & 7 \\
\hline
\end{tabular}

Sumber : Hasil penelitian (2020)

\section{Hasil Pengujian Slump}

Pengujian slump dilakukan untuk mengetahui tingkat kekentalan adukan beton, yang dapat menggambarkan kemudahan pengerjaan (workability) beton. Adapun hasil dari pengujian slump dijelaskan pada Tabel 11.

Tabel 11. Hasil Pengujian Slump

\begin{tabular}{|c|c|c|}
\hline No. & $\begin{array}{c}\text { Persentase abu ban bekas } \\
(\boldsymbol{\%})\end{array}$ & $\begin{array}{c}\text { Nilai slump } \\
(\mathbf{c m})\end{array}$ \\
\hline 1. & 0 & 5,8 \\
\hline 2. & 3 & 4,9 \\
\hline 3. & 6 & 3,5 \\
\hline 4. & 9 & 3 \\
\hline
\end{tabular}

Sumber : Hasil Penelitian (2020)

Berdasarkan Tabel 11. didapatkan bahwa nilai slump berkurang seiring dengan penambahan volume abu ban bekas. Hal ini menunjukkan bahwa semakin besar penambahan abu ban bekas pada campuran beton, maka akan menurunkan sifat workability/kelecakan beton tersebut.

\section{Hasil Pengujian Kuat Tekan Beton}

Hasil pengujian kuat tekan beton terhadap beton dengan campuran abu bekas ban $0 \%$ atau beton normal dijabarkan pada Tabel 12. Hasil pengujian kuat tekan beton terhadap beton dengan campuran abu ban bekas 3\%, 6\% dan 9\% dijabarkan pada Tabel 13, Tabel 14 danTabel15. 
Jurnal Visi Eksakta (JVIEKS)

Vol.2, No.2, Juli 2021, pp. 141-149

https://ejournal.uhn.ac.id/index.php/eksakta

147

Tabel 12. Hasil Pengujian Kuat Tekan Beton Normal

\begin{tabular}{|c|c|c|c|c|c|c|c|c|c|c|c|c|}
\hline \multirow[b]{2}{*}{$\begin{array}{c}\text { Benda } \\
\text { uji }\end{array}$} & \multirow[b]{2}{*}{$\begin{array}{c}\text { Berat } \\
\text { (gram) }\end{array}$} & \multirow[b]{2}{*}{$\begin{array}{l}\text { Beban } \\
(\mathbf{N})\end{array}$} & \multirow[b]{2}{*}{$\mathbf{m}^{2}$} & \multicolumn{4}{|c|}{ Umur benda uji (hari) } & \multirow[b]{2}{*}{$\mathbf{f}^{\prime} \mathbf{u}$} & \multirow{2}{*}{$\begin{array}{c}\mathbf{f}^{\prime} \mathbf{c i} \\
\left(\mathrm{N} / \mathbf{m m}^{2}\right)\end{array}$} & \multirow{2}{*}{$\begin{array}{c}f^{\prime} c r \\
(N / m \\
\left.m^{2}\right)\end{array}$} & \multirow[b]{2}{*}{$\begin{array}{l}\text { S } \\
\mathbf{D}\end{array}$} & \multirow[b]{2}{*}{$\begin{array}{c}\mathbf{f}^{\prime} \mathbf{c} \\
\left(\mathbf{N} / \mathbf{m m}^{2}\right)\end{array}$} \\
\hline & & & & 7 & 14 & 21 & 28 & & & & & \\
\hline 1 & 12600 & 400000 & 17662,5 & $\mathrm{~V}$ & & & & 0,65 & 35 & \multirow{12}{*}{$\begin{array}{c}29.65 \\
2\end{array}$} & \multirow{12}{*}{$\begin{array}{l}2, \\
56\end{array}$} & \multirow{12}{*}{25,45} \\
\hline 2 & 12600 & 425000 & 17662,5 & V & & & & 0,65 & 37 & & & \\
\hline 3 & 12800 & 440000 & 17662,5 & $\mathrm{~V}$ & & & & 0,65 & 38 & & & \\
\hline 4 & 12600 & 450000 & 17662,5 & & $\mathrm{~V}$ & & & 0,88 & 29 & & & \\
\hline 5 & 12200 & 455000 & 17662,5 & & V & & & 0,88 & 29 & & & \\
\hline 6 & 12600 & 490000 & 17662,5 & & $\mathrm{~V}$ & & & 0,88 & 32 & & & \\
\hline 7 & 12800 & 435000 & 17662,5 & & & $\mathrm{~V}$ & & 0,95 & 26 & & & \\
\hline 8 & 12400 & 440000 & 17662,5 & & & $\mathrm{~V}$ & & 0,95 & 26 & & & \\
\hline 9 & 12800 & 450000 & 17662,5 & & & $\mathrm{~V}$ & & 0,95 & 26,81 & & & \\
\hline 10 & 12800 & 420000 & 17662,5 & & & & $\mathrm{~V}$ & 1 & 23,77 & & & \\
\hline 11 & 12800 & 430000 & 17662,5 & & & & $\mathrm{~V}$ & 1 & 24 & & & \\
\hline 12 & 12800 & 440000 & 17662,5 & & & & $\mathrm{~V}$ & 1 & 25 & & & \\
\hline
\end{tabular}

Sumber : Hasil penelitian (2020)

Tabel 13. Hasil Pengujian Kuat Tekan Beton Campuran Abu Ban Bekas 3\%

\begin{tabular}{|c|c|c|c|c|c|c|c|c|c|c|c|c|}
\hline \multirow{2}{*}{$\begin{array}{c}\text { Benda } \\
\text { uji }\end{array}$} & \multirow{2}{*}{$\begin{array}{l}\text { Berat } \\
\text { (gram) }\end{array}$} & \multirow{2}{*}{$\begin{array}{l}\text { Beban } \\
(\mathrm{N})\end{array}$} & \multirow[t]{2}{*}{$\mathbf{m}^{2}$} & \multicolumn{4}{|c|}{$\begin{array}{c}\text { Umur benda uji } \\
\text { (hari) }\end{array}$} & \multirow[t]{2}{*}{$\mathbf{f}^{\prime} \mathbf{u}$} & \multirow{2}{*}{$\begin{array}{c}\mathbf{f}^{\prime} \mathbf{c i} \\
\left(\mathbf{N} / \mathbf{m m}^{2}\right)\end{array}$} & \multirow{2}{*}{$\begin{array}{c}\mathbf{f}^{\prime} \mathbf{c r} \\
\left(\mathrm{N} / \mathbf{m m}^{2}\right)\end{array}$} & \multirow[t]{2}{*}{ SD } & \multirow{2}{*}{$\begin{array}{c}\mathbf{f}^{\prime} \mathbf{c} \\
\left(\mathbf{N} / \mathbf{m m}^{2}\right)\end{array}$} \\
\hline & & & & 7 & 14 & 21 & 28 & & & & & \\
\hline 1 & 12900 & 455000 & 17662,5 & $\mathrm{~V}$ & & & & 0,65 & 39,6 & \multirow{12}{*}{32,6} & \multirow{12}{*}{2,71} & \multirow{12}{*}{28,15} \\
\hline 2 & 12600 & 290000 & 17662,5 & $\mathrm{~V}$ & & & & 0,65 & 25,2 & & & \\
\hline 3 & 12000 & 395000 & 17662,5 & $\mathrm{~V}$ & & & & 0,65 & 34,4 & & & \\
\hline 4 & 12400 & 715000 & 17662,5 & & $\mathrm{~V}$ & & & 0,88 & 46 & & & \\
\hline 5 & 12400 & 315000 & 17662,5 & & V & & & 0,88 & 20,2 & & & \\
\hline 6 & 12400 & 600000 & 17662,5 & & $\mathrm{~V}$ & & & 0,88 & 38,6 & & & \\
\hline 7 & 12200 & 580000 & 17662,5 & & & $\mathrm{~V}$ & & 0,95 & 34,5 & & & \\
\hline 8 & 12200 & 615000 & 17662,5 & & & V & & 0,95 & 36,6 & & & \\
\hline 9 & 12800 & 450000 & 17662,5 & & & V & & 0,95 & 26,8 & & & \\
\hline 10 & 12400 & 570000 & 17662,5 & & & & $\mathrm{~V}$ & 1 & 32,2 & & & \\
\hline 11 & 12400 & 540000 & 17662,5 & & & & V & 1 & 30,5 & & & \\
\hline 12 & 12400 & 470000 & 17662,5 & & & & V & 1 & 26,6 & & & \\
\hline
\end{tabular}

Sumber : Hasil penelitian (2020)

Tabel 14. Hasil Pengujian Kuat Tekan Beton Campuran Abu Ban Bekas 6\%

\begin{tabular}{|c|c|c|c|c|c|c|c|c|c|c|c|c|}
\hline \multirow{2}{*}{$\begin{array}{c}\text { Benda } \\
\text { uji }\end{array}$} & \multirow{2}{*}{$\begin{array}{c}\text { Berat } \\
\text { (gram) }\end{array}$} & \multirow{2}{*}{$\begin{array}{c}\text { Beban } \\
(\mathbf{N})\end{array}$} & \multirow[t]{2}{*}{$\mathbf{m}^{2}$} & \multicolumn{4}{|c|}{$\begin{array}{c}\text { Umur benda } \\
\text { uji (hari) }\end{array}$} & \multirow[t]{2}{*}{$\mathbf{f}^{\prime} \mathbf{u}$} & \multirow{2}{*}{$\begin{array}{c}\mathbf{f}^{\prime} \mathbf{c i} \\
\left(\mathrm{N} / \mathrm{mm}^{2}\right)\end{array}$} & \multirow{2}{*}{$\begin{array}{c}\mathbf{f}^{\prime} \mathbf{c r} \\
\left(\mathbf{N} / \mathbf{m m}^{2}\right)\end{array}$} & \multirow[t]{2}{*}{ SD } & \multirow{2}{*}{$\begin{array}{c}\mathbf{f}^{\prime} \mathbf{c} \\
\left(\mathrm{N} / \mathbf{m m}^{2}\right)\end{array}$} \\
\hline & & & & 7 & 14 & 21 & 28 & & & & & \\
\hline 1 & 12200 & 406000 & 17662,5 & $\mathrm{~V}$ & & & & 0,65 & 35,3 & \multirow{6}{*}{27.383} & \multirow{6}{*}{2,39} & \multirow{6}{*}{23,46} \\
\hline 2 & 12400 & 315000 & 17662,5 & V & & & & 0,65 & 27,4 & & & \\
\hline 3 & 12200 & 325000 & 17662,5 & $\mathrm{~V}$ & & & & 0,65 & 28,3 & & & \\
\hline 4 & 12600 & 360000 & 17662,5 & & $\mathrm{~V}$ & & & 0,88 & 23,1 & & & \\
\hline 5 & 12400 & 500000 & 17662,5 & & V & & & 0,88 & 32,1 & & & \\
\hline 6 & 12000 & 390000 & 17662,5 & & V & & & 0,88 & 25 & & & \\
\hline
\end{tabular}

Received, $06^{\text {th }}$ February 2020; 15 $5^{\text {st }}$ March Revised, 2021; Accepted July, 2021 
Jurnal Visi Eksakta (JVIEKS)

Vol.2, No.2, Juli 2021, pp. 141-149

https://ejournal.uhn.ac.id/index.php/eksakta

\begin{tabular}{|c|c|c|c|c|c|c|c|c|c|c|c|}
\hline 7 & 12800 & 520000 & 17662,5 & & & $\mathrm{~V}$ & & 0,95 & 30,9 & & \\
\hline 8 & 12200 & 495000 & 17662,5 & & & $\mathrm{~V}$ & & 0,95 & 29,5 \\
\hline 9 & 12600 & 315000 & 17662,5 & & & $\mathrm{~V}$ & & 0,95 & 18,7 \\
\hline 10 & 12400 & 490000 & 17662,5 & & & & $\mathrm{~V}$ & 1 & 27,7 \\
\hline 11 & 12400 & 430000 & 17662,5 & & & & $\mathrm{~V}$ & 1 & 24,3 \\
\hline 12 & 12400 & 465000 & 17662,5 & & & & $\mathrm{~V}$ & 1 & 26,3 & & \\
\end{tabular}

Sumber : Hasil penelitian (2020)

Tabel 15. Hasil Pengujian Kuat Tekan Beton Campuran Abu Ban Bekas 9\%

\begin{tabular}{|c|c|c|c|c|c|c|c|c|c|c|c|c|}
\hline \multirow{2}{*}{$\begin{array}{c}\text { Benda } \\
\text { uji }\end{array}$} & \multirow{2}{*}{$\begin{array}{l}\text { Berat } \\
\text { (gram) }\end{array}$} & \multirow{2}{*}{$\begin{array}{l}\text { Beban } \\
(\mathbf{N})\end{array}$} & \multirow[t]{2}{*}{$\mathbf{m}^{2}$} & \multicolumn{4}{|c|}{$\begin{array}{c}\text { Umur benda uji } \\
\text { (hari) }\end{array}$} & \multirow[t]{2}{*}{$\mathbf{f}^{\prime} \mathbf{u}$} & \multirow{2}{*}{$\begin{array}{c}\mathbf{f}^{\prime} \mathbf{c i} \\
\left(\mathrm{N} / \mathbf{m m}^{2}\right)\end{array}$} & \multirow{2}{*}{$\begin{array}{c}\mathbf{f}^{\prime} \mathbf{c r} \\
\left(\mathrm{N} / \mathbf{m m}^{2}\right)\end{array}$} & \multirow[t]{2}{*}{ SD } & \multirow{2}{*}{$\begin{array}{c}\mathbf{f}^{\prime} \mathbf{c} \\
\left(\mathbf{N} / \mathbf{m m}^{2}\right)\end{array}$} \\
\hline & & & & 7 & 14 & 21 & 28 & & & & & \\
\hline 1 & 12200 & 370000 & 17662,5 & $\mathrm{~V}$ & & & & 0,65 & 32,2 & \multirow{12}{*}{22,084} & \multirow{12}{*}{2,12} & \multirow{12}{*}{18,60} \\
\hline 2 & 12400 & 315000 & 17662,5 & V & & & & 0,65 & 27,4 & & & \\
\hline 3 & 12200 & 265000 & 17662,5 & $\mathrm{~V}$ & & & & 0,65 & 23 & & & \\
\hline 4 & 11800 & 385000 & 17662,5 & & $\mathrm{~V}$ & & & 0,88 & 24,7 & & & \\
\hline 5 & 12400 & 365000 & 17662,5 & & $\mathrm{~V}$ & & & 0,88 & 23,4 & & & \\
\hline 6 & 12200 & 350000 & 17662,5 & & $\mathrm{~V}$ & & & 0,88 & 22,5 & & & \\
\hline 7 & 12400 & 390000 & 17662,5 & & & $\mathrm{~V}$ & & 0,95 & 23,2 & & & \\
\hline 8 & 12000 & 285000 & 17662,5 & & & $\mathrm{~V}$ & & 0,95 & 16,9 & & & \\
\hline 9 & 12400 & 365000 & 17662,5 & & & V & & 0,95 & 21,7 & & & \\
\hline 10 & 12200 & 270000 & 17662,5 & & & & $\mathrm{~V}$ & 1 & 15,2 & & & \\
\hline 11 & 12400 & 365000 & 17662,5 & & & & $\mathrm{~V}$ & 1 & 20,6 & & & \\
\hline 12 & 12200 & 360000 & 17662,5 & & & & $\mathrm{~V}$ & 1 & 20,3 & & & \\
\hline
\end{tabular}

Sumber : Hasil penelitian (2020)

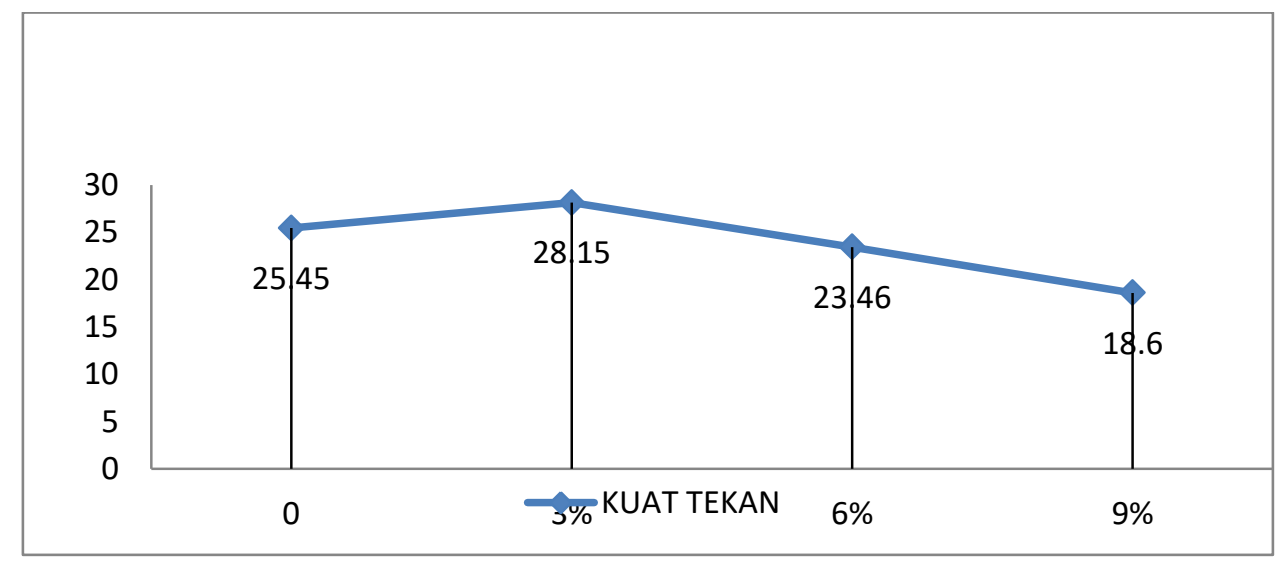

Gambar 2. Grafik Kuat Tekan Beton (f'c) Normaldan Beton Campuran Abu Ban Bekas

Sumber : Hasil penelitian (2020) 
Berdasarkan Tabel dan Grafik di atas, dapat dilihat bahwa pada beton normal (abu 0\%) kuat tekan yang dihasilkan adalah 25,45 MPa lebih besar dari kuat tekan yang direncanakan. Pada beton campuran abu ban bekas 3\% kuat tekan yang dihasilkan adalah 28,15 MPa lebih besar dari kuat tekan yang direncanakan. Sedangkan pada beton campuran abu ban bekas 6\% kuat tekan yang dihasilkan adalah 23,46 MPa lebih kecil dibandingkan kuat tekan beton yang direncanakan dan pada beton campuran abu ban bekas $9 \%$ kuat tekan yang dihasilkan adalah 18,60 MPa jauh lebih kecil dari kuat tekan yang direncakan. Hasil penelitian uji kuat tekan beton yang dihasilkan persentase paling optimum yaitu beton dengan campuran abu ban bekas $3 \%$ yaitu 28,15 MPa.

\section{KESIMPULAN}

Berdasarkan penelitian yang telah dilakukan maka dapat ditarik beberapa kesimpulan di antaranya adalah berdasarkan uji kehalusan didapatkan hasil bahwa semen jauh lebih halus dibandingkan abu ban bekas sehingga abu ban bekas dapat mengisi pori-pori agregat dan persentase abu ban bekas yang paling optimum yang dapat digunakan pada campuran adukan beton adalah beton dengan campuran adukan ban bekas sebesar $3 \%$ yang memiliki kuat tekan sebesar 28,15 MPa.

\section{DAFTAR PUSTAKA}

Anonim. (1990), Tata Cara Rencana Pembuatan Campuran Beton Normal, Departemen Pekerjaan Umum. Yayasan Lembaga Penyelidikan Masalah Bangunan. Bandung Badan Standarisasi Nasional. (2004), Semen Portland, Badan Standarisasi Nasional. Jakarta Mulyono, Tri. (2004). Teknologi Beton. Penerbit ANDI. Yogyakarta.

Tjokrodimuljo, K. (2003), Teknologi Bahan Konstruksi, Bahan Ajar. Jurusan Teknik Sipil. Fakultas Teknik. UGM. Yogyakarta. 